\title{
Crosstalk between mitogen-activated protein kinase inhibitors and transforming growth factor- $\beta$ signaling results in variable activation of human dermal fibroblasts
}

\author{
DAVID M. DOLIVO, SARA A. LARSON and TANJA DOMINKO
}

Department of Biology and Biotechnology, Worcester Polytechnic Institute, Worcester, MA 01609, USA

Received July 17, 2018; Accepted October 19, 2018

DOI: $10.3892 /$ ijmm.2018.3949

\begin{abstract}
Fibroblast activation is a key step in the establishment of skin fibrosis induced by acute injury, and it is characterized by the differentiation of plastic resident tissue fibroblasts into contractile, extracellular matrix-secreting myofibroblasts. As fibroblast activation must be regulated in vivo, fibroblasts receive signals from the surrounding environment that initiate their fibrotic program. Thus, the present study investigated the effects of mitogen-activated protein kinase (MAPK) signaling pathways on fibroblast activation. It was demonstrated in primary human dermal fibroblasts that small molecule-mediated inhibition of extracellular signal-regulated kinase (ERK) and c-Jun N-terminal kinase (JNK) potentiated fibroblast activation, and that small molecule-mediated inhibition of p38 antagonized fibroblast activation. ERK and JNK inhibition cooperatively enhanced fibroblast activation mediated by treatment with exogenous transforming growth factor (TGF)- $\beta 1$, and p38 inhibition antagonized ERK inhibitor-mediated or JNK inhibitor-mediated fibroblast activation. Transcript analysis demonstrated that ERK and JNK inhibitor-mediated fibroblast activation was accompanied by distinct changes in the expression of TGF- $\beta$-associated ligands and receptors, and that p38 inhibitor-mediated antagonism of fibroblast activation was accompanied by a distinct expression paradigm of TGF- $\beta$-associated genes, including upregulation of betaglycan. ERK inhibitor-mediated and JNK inhibitor-mediated fibroblast activation was partially antagonized by small molecule-mediated inhibition of TGF- $\beta$ receptor $(\mathrm{R}) 1$, indicating that these mechanisms of fibroblast activation are partially dependent on TGF- $\beta /$ TGF- $\beta$ R signaling. These data collectively demonstrate and provide partial explanations of the varied effects and pathway dependencies of MAPK inhibitor-mediated effects on fibroblast activation.
\end{abstract}

Correspondence to: Dr Tanja Dominko, Department of Biology and Biotechnology, Worcester Polytechnic Institute, 100 Institute Road, Worcester, MA 01609, USA

E-mail: tdominko@wpi.edu

Key words: extracellular signal-regulated kinase, fibroblast, fibrosis, mitogen-activated protein kinase, myofibroblast, p38

\section{Introduction}

Fibroproliferative diseases, diseases characterized by extensive tissue fibrosis, are substantial contributors to mortality in the developed world (1). Tissue fibrosis refers to a process by which a damaged organ undergoes a wound repair program, but instead of regenerating native tissue, it creates a collagen-rich scar that fails to recapitulate the mechanical environment and functional capacity of the original tissue. Various diverse organs undergo fibrosis, including the liver, heart, kidney and skin (2). However, despite there being numerous crucial differences among fibrotic pathologies of various organs, the ubiquity of the fibrotic response across diverse organ systems demonstrates that there are commonalities amongst these tissues to the fibrotic program as well (2). One of these commonalities is the paradigm of fibroblast activation, during which a fibroblast differentiates and undergoes a phenotypic switch to become a contractile myofibroblast with a distinct secretory profile of type I collagen and fibronectin, as well as the expression of smooth muscle markers, including, smooth muscle $\alpha$ actin ( $\alpha$-SMA) (3).

As myofibroblast contractile activity and excessive deposition of fibrotic extracellular matrix (ECM) can frequently be detrimental to health, and is regulated by the cellular environment, fibroblasts must only become activated into myofibroblasts during scenarios in which tissue repair is necessary (3). A class of pathways responsible for transducing cellular signals from the extracellular environment is known as the mitogen activated protein kinases (MAPKs) (4). MAPK pathways have been implicated in the development or prevention of fibrotic phenotypes at the cellular level and in various tissues, partially through their ability to propagate signaling initiated by growth factors in the extracellular milieu, including the ubiquitous pro-fibrotic transforming growth factor beta (TGF- $\beta$ ) pathway (5-15). Thus, an understanding of the interplay of various stimulating factors in the wound microenvironment is paramount to the understanding of healthy and pathological wound healing. Despite this, the manner in which complex environmental signals are integrated into a coherent wound healing response, characterized by defined actions of particular effectors cells, is not well-understood. Thus, the aim of the present study was to improve the understanding of the effects of MAPK pathways through the use of chemical inhibitors, in conjunction with each other and with TGF- $\beta$ signaling 
mediators, in order to improve the understanding of a number of signaling processes resulting in fibroblast activation.

\section{Materials and methods}

Reagents. The primary antibodies used were the following: $\alpha$-SMA (cat. no. sc-32251; 1:1,000 for western blotting, 1:100 for fluorescence microscopy), collagen I (cat. no. sc-8783; 1:100), ED-A fibronectin (ED-A Fn; cat. no. sc-59826; 1:100), Histone H3 (cat. no. sc-8654-R; 1:1,000) (all from Santa Cruz Biotechnology, Inc., Dallas, TX, USA), Calponin (clone: CALP; 1:1,000; Dako; Agilent Technologies, Inc., Santa Clara, CA, USA), SM22 $\alpha$ (cat. no. VPA00048KT; 1:1,000; Bio-Rad Laboratories, Inc., Hercules, CA, USA) and p-ERK1/2 (cat. no. 4370; 1:1,000; Cell Signaling Technology, Inc., Danvers, MA, USA). The secondary antibodies used were AlexaFluor ${ }^{\circledR} 488$-conjugated donkey anti-goat IgG (cat. no. A-11055) or AlexaFluor488-conjugated goat anti-mouse IgG (cat. no. A-11001) (Invitrogen; Thermo Fisher Scientific, Inc., Waltham, MA, USA) for immunofluorescence and horseradish peroxidase (HRP)-conjugated for western blotting (Bio-Rad Laboratories, Inc.). The MAPK inhibitors used were U0126, SP600125 and SB202190 (all from Santa Cruz Biotechnology, Inc.). The TGF- $\beta$ R1 inhibitor used was RepSox (Tocris Biosceince, Bristol, UK). The recombinant human TGF- $\beta 1$ used was purchased from Peprotech, Inc. (Rocky Hill, NJ, USA). The recombinant human fibroblast growth factor 2 used was purchased from Cell Signaling Technology, Inc. AlexaFluor 568-conjugated Phalloidin (cat. no. A12380) was obtained from Invitrogen (Thermo Fisher Scientific, Inc.) and used to stain F-actin.

Cell culture. CRL-2097 and CRL-2352 human dermal fibroblasts were obtained from American Type Culture Collection (Manassas, VA, USA), and CT-1005 human dermal fibroblasts were obtained from the University of Massachusetts Medical School tissue distribution program (Worcester, MA, USA), derived from the dermis of a human female patient undergoing a panniculectomy. Fibroblasts were cultured in 1:1 Dulbecco's modified Eagle's medium:Ham's F12 supplemented with $4 \mathrm{mM}$ L-glutamine (Corning Incorporated, Corning, NY, USA) and 10\% Fetal Clone III (Hyclone; GE Healthcare Life Sciences, Logan, UT, USA) on Nunclon Delta tissue culture plastic (Thermo Fisher Scientific, Inc.). Cultures were incubated at $37^{\circ} \mathrm{C}$ in an atmosphere containing $5 \% \mathrm{CO}_{2}$ and high humidity, and in the presence or absence of MAPK inhibitors, recombinant FGF2 or TGF- $\beta 1$, or RepSox. Cells were processed on day 4 in culture, unless otherwise indicated, for analysis, by trypsinizing cells to collect them, washing once with PBS, pelleting by centrifugation for $5 \mathrm{~min}$ at $200 \mathrm{x}$ g at room temperature, and snap freezing in liquid nitrogen for storage at $-80^{\circ} \mathrm{C}$.

Indirect flow cytometry. CRL-2097 fibroblasts were harvested with $0.05 \%$ trypsin and washed twice in Dulbecco's PBS (DPBS; Corning Incorporated). Cells were fixed at $4^{\circ} \mathrm{C}$ for $20 \mathrm{~min}$ in cold methanol and washed in 1X DPBS. Blocking was performed for $30 \mathrm{~min}$ at room temperature in $5 \%$ bovine serum albumin (BSA; VWR International, Leicestershire, UK) in PBS with $0.05 \%$ Tween-20 (PBS-T) followed by a
30 min incubation in a primary antibody solution (1:200 dilution of $\alpha$-SMA antibody) in PBS-T at room temperature. Cells were then washed again once in $1 \mathrm{X}$ DPBS and resuspended in a 1:500 dilution of secondary antibody solution in PBS-T (AlexaFluor488-conjugated goat anti-mouse IgG). Cells were counterstained with $500 \mathrm{ng} / \mathrm{ml}$ propidium iodide for $15 \mathrm{~min}$ at room temperature in the dark and analyzed on an Accuri C6 flow cytometer using Accuri-C6 analysis software (version 1.0.264.21; BD Biosciences, Franklin Lakes, NJ, USA). A total of 20,000 events were collected per sample.

RNA isolation and reverse transcription-quantitative polymerase chain reaction ( $R T-q P C R)$. RNA was isolated from snap-frozen CRL-2097 cell pellets with an E.Z.N.A. DNA/RNA Isolation kit (Omega Bio-Tek, Inc., Norcross, GA, USA), according to manufacturer's protocols. Concentration of RNA was determined using a NanoDrop 2000 spectrophotometer (Thermo Fisher Scientific, Inc.). Complementary DNA (cDNA) was synthesized using a qScript cDNA Supermix (Quantabio, Beverly, MA, USA), according to manufacturer's protocols, and stored at $-20^{\circ} \mathrm{C}$. PCR reactions were conducted according to the manufacturer's protocols using an AB 7500 (Applied Biosystems; Thermo Fisher Scientific, Inc.) with PowerUp SYBR ${ }^{\circledR}$ Master mix (Thermo Fisher Scientific, Inc.), using $5 \mathrm{ng}$ cDNA/reaction and $500 \mathrm{nM}$ concentration/primer. Primer sequences are detailed in Table I. Relative expression fold changes were calculated using the $\Delta \Delta \mathrm{C}_{\mathrm{q}}$ method (16).

SDS-PAGE and western blotting. Protein was isolated from CRL-2097, CRL-2352 or CT-1005 fibroblasts using cold 2X Laemmli sample buffer supplemented with protease and phosphatase inhibitor cocktail (Thermo Fisher Scientific, Inc.). Protein concentration was quantified with a Bradford protein assay (Bio-Rad Laboratories, Inc.). Cells were lysed on ice and DNA was sheared on ice using a Missonix CL-2000 ultrasonic cell disruptor. Samples were boiled for $10 \mathrm{~min}$ on a heat block, and then $4 \mu \mathrm{g}$ total protein/sample was separated on $12 \%$ SDS-PAGE. For western blot analysis, protein from the gel was transferred to a polyvinylidene fluoride membrane (EMD Millipore, Billerica, MA, USA) using a mini-PROTEAN Tetra Cell (Bio-Rad Laboratories, Inc.). The membrane was blocked in 5\% fat-free dry milk in buffer containing $1 \mathrm{X}$ TBS and $0.1 \%$ Tween-20 (TBS-T; $\mathrm{pH}=8.0$ ) for $1 \mathrm{~h}$ at room temperature. The membrane was incubated and rotated overnight at $4{ }^{\circ} \mathrm{C}$ in the primary antibody solution ( $\alpha$-SMA, Histone H3, Calponin, SM22 $\alpha$ or p-ERK1/2) at a pre-determined, antibody-specific dilution in $1 \%$ fat-free dry milk in TBS-T. The membrane was washed four times for 10 min each in TBS-T and incubated in a species-specific, HRP-conjugated secondary antibody (dilution, $1: 5,000)$ in $1 \%$ fat-free dry milk in TBS-T and rotated at room temperature for $2 \mathrm{~h}$. Subsequently, the membrane was washed four times for $10 \mathrm{~min}$ each in TBS-T, and the signal was visualized with a ChemiDoc XRS system (Bio-Rad Laboratories, Inc.) using SuperSignal West Dura Extended Duration Substrate (Thermo Fisher Scientific, Inc.). Densitometry was performed in ImageJ 1.8.0 (National Institutes of Health, Bethesda, MD, USA).

Fluorescent microscopy. CRL-2097 fibroblasts were plated on glass coverslips inside of 24-well tissue culture plates for 4 days 
Table I. Primer sequences for reverse transcription-quantitative polymerase chain reaction.

\begin{tabular}{|c|c|c|c|c|}
\hline $\begin{array}{l}\text { Gene } \\
\text { name }\end{array}$ & $\begin{array}{l}\text { Protein } \\
\text { encoded }\end{array}$ & Forward primer $\left(5^{\prime}-3^{\prime}\right)$ & Reverse primer $\left(5^{\prime}-3^{\prime}\right)$ & $\begin{array}{c}\text { Amplicon } \\
\text { size (bp) }\end{array}$ \\
\hline ACTA2 & $\alpha-\mathrm{SMA}$ & ACTGCCTTGGTGTGTGACAA & CACCATCACCCCCTGATGTC & 120 \\
\hline CNN1 & Calponin & AGGTTAAGAACAAGCTGGCCC & GAGGCCGTCCATGAAGTTGT & 113 \\
\hline$T A G L N$ & SM22 $\alpha$ & CACAAGGTGTGTGTAAGGGTG & GGCTCATGCCATAGGAAGGAC & 132 \\
\hline CCN2 & $\mathrm{CCN} 2$ & GTGCCTGCCATTACAACTGTC & TCTCACTCTCTGGCTTCATGC & 98 \\
\hline$E D-A F n$ & ED-A Fn & CAGTGGAGTATGTGGTTAGTGTC & GTGACCTGAGTGAACTTCAGG & 119 \\
\hline CollA1 & Col1A1 & GTCAGGCTGGTGTGATGGG & GCCTTGTTCACCTCTCTCGC & 182 \\
\hline CollA2 & Col1A2 & CTGGAGAGGCTGGTACTGCT & AGCACCAAGAAGACCCTGAG & 62 \\
\hline Col3Al & Col3A1 & GGACACAGAGGCTTCGATGG & CTCGAGCACCGTCATTACCC & 190 \\
\hline$M M P 1$ & MMP1 & GCATATCGATGCTGCTCTTTC & GATAACCTGGATCCATAGATCGTT & 110 \\
\hline$L O X$ & LOX & СTCTTGCTGTCCTCCGCTC & ATCTTGGTCGGCTGGGTAAG & 155 \\
\hline$M Y O C D$ & MYOCD & AGAGGCCATAAAAGGTAACCAGG & GGGGGTCTTCACTTCGAGTC & 116 \\
\hline$T G F B 1$ & TGF- $\beta 1$ & CATTGGTGATGAAATCCTGGT & TGACACTCACCACATTGTTTTTC & 110 \\
\hline$T G F B 2$ & TGF- $\beta 2$ & GAGCGACGAAGAGTACTACG & TTGTAACAACTGGGCAGACA & 89 \\
\hline$T G F B R 1$ & TGF- $\beta$ R 1 & GCAGACTTAGGACTGGCAGTAAG & AGAACTTCAGGGGCCATGT & 104 \\
\hline$T G F B R 2$ & TGF- $\beta$ R2 & TGGACCCTACTCTGTCTGTG & CTGGAGCCATGTATCTTGCAG & 72 \\
\hline$T G F B R 3$ & Betaglycan & CTGGTGTGGCATCTGAAGAC & GGACCACAGAACCCTCAGAC & 79 \\
\hline$G A P D H$ & GAPDH & GAGTCCACTGGCGTCTTCAC & TTCACACCCATGACGAACAT & 119 \\
\hline
\end{tabular}

ACTA2, $\alpha$-SMA; $\alpha$-SMA, smooth muscle $\alpha$ actin; CNN1, calponin 1; TAGLN, transgelin; CCN2, connective tissue growth factor; CTGF, CCN2; ED-A Fn, ED-A fibronectin; Col1A1, collagen type $1 \alpha$ 1; MMP1, matrix metallopeptidase 1; LOX, lysyl oxidase; MYOCD, myocardin; TGF- $\beta 1$, transforming growth factor- $\beta 1$; TGFB1, TGF- $\beta 1$; TGF- $\beta$ R1, TGF- $\beta$ receptor 1 ; TGFBR1, TGF- $\beta$ R1.

in the presence or absence of $10 \mu \mathrm{M}$ MAPK inhibitors and/or $10 \mathrm{ng} / \mathrm{ml}$ exogenous recombinant human TGF- $\beta 1$. At the time of analysis, cells were fixed in $4 \%$ paraformaldehyde at room temperature for $20 \mathrm{~min}$, and then permeabilized with $0.1 \%$ Triton X-100 in 1X PBS. Blocking was performed in 5\% BSA in PBS-T for $30 \mathrm{~min}$ at room temperature. Subsequently, Cells were incubated overnight at $4^{\circ} \mathrm{C}$ with agitation in $250 \mu \mathrm{l} /$ well of primary antibody ( $\alpha$-SMA, collagen I or ED-A fibronectin) in PBS-T using antibody-specific dilutions. Cells were then washed three times for 5 min each in PBS-T prior to the addition of a 1:500 dilution of AlexaFluor 488-conjugated secondary antibodies or AlexaFluor-conjugated phalloidin (both purchased from Invitrogen; Thermo Fisher Scientific, Inc.), incubated at room temperature in the dark for $30 \mathrm{~min}$, and protected from light thereafter. Cells were then washed three times for $5 \mathrm{~min}$ each in PBS-T prior to being incubated in $500 \mathrm{ng} / \mathrm{ml}$ Hoechst 33342 in 1X PBS-T (Thermo Fisher Scientific, Inc.) for $15 \mathrm{~min}$ at room temperature to stain the nuclei. Cells were washed twice for 5 min each in PBS and coverslips were mounted onto glass slides using Prolong Gold (Thermo Fisher Scientific, Inc.) and stored at $4^{\circ} \mathrm{C}$ until imaging. Images were collected using an Axiovert 200M (Carl Zeiss AG, Oberkochen, Germany) at x20 magnification or using identical exposure times and settings between treatments, to allow for direct qualitative comparison of protein expression between different treatments.

Statistical analysis. All statistics were performed in GraphPad Prism 7 (GraphPad Software, Inc., La Jolla, CA, USA). All statistics were performed with Student's t-tests or one-way analysis of variance with Holm-Sidak post-hoc analysis. $\mathrm{P}<0.05$ was considered to indicate a statistically significant difference. All data are presented as the mean \pm standard deviation.

\section{Results}

Fibroblast activation is promoted by inhibition of ERK or $J N K$ and antagonized by inhibition of p38. Firstly, the effects of MAPK inhibitors on activation of human fibroblasts was investigated. Treatment of CRL-2097 human neonatal foreskin fibroblasts with $10 \mu \mathrm{M}$ U0126 (ERK inhibitor) or $10 \mu \mathrm{M}$ SP600125 (JNK inhibitor) was sufficient to induce upregulation of three myofibroblast-associated transcripts, $\alpha$-SMA (ACTA2), calponin 1 (CNN1), and transgelin (TAGLN), the genes that encode $\alpha$-SMA, calponin, and TAGLN (SM22 $\alpha$ ), respectively. In contrast, treatment with $10 \mu \mathrm{M}$ SB202190 (p38 inhibitor) significantly downregulated the expression of these transcripts, compared with the control fibroblasts $(\mathrm{P}<0.05)$ (Fig. 1A). Western blot analysis coincided with the RT-qPCR data and demonstrated that treatment with these inhibitors upregulated or downregulated the expression of the myofibroblast markers encoded by these genes in a qualitatively similar manner (Fig. 1B). In order to improve the understanding of the effects of MAPK inhibition on expression of $\alpha$-SMA, the major myofibroblast marker, at the cellular level, indirect flow cytometry was performed. Analysis of the data revealed that the mean level of $\alpha$-SMA protein expression/cell was significantly increased in cells cultured in the presence of ERK or JNK inhibitors, or in the presence of exogenous TGF- $\beta 1$, and significantly decreased in the presence of $\mathrm{p} 38$ inhibitor, compared with fibroblasts cultured under control 


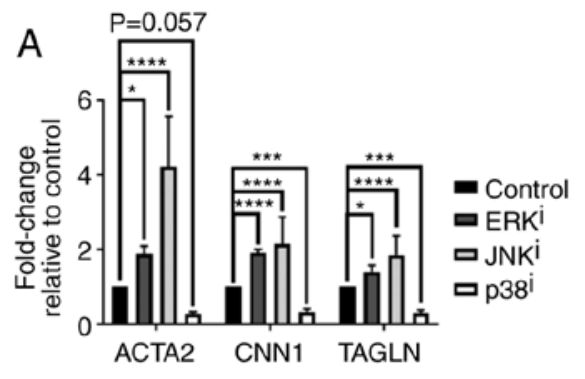

$\mathrm{B}$

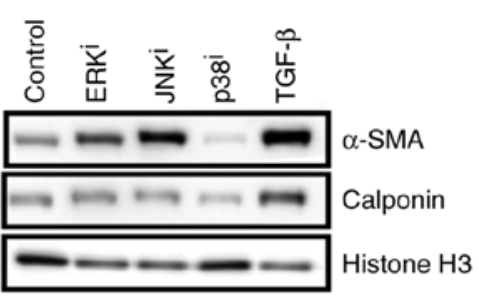

C

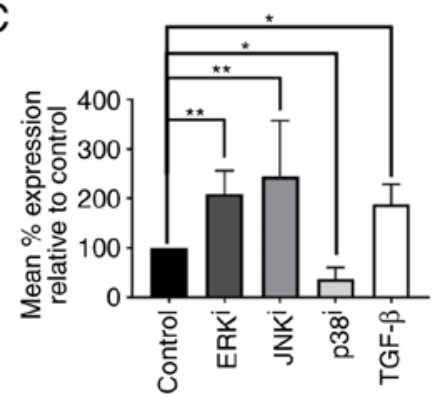

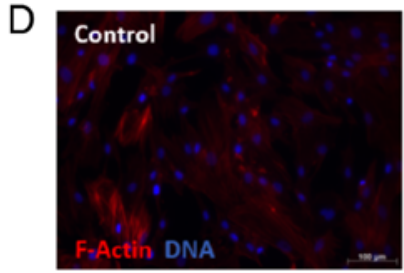
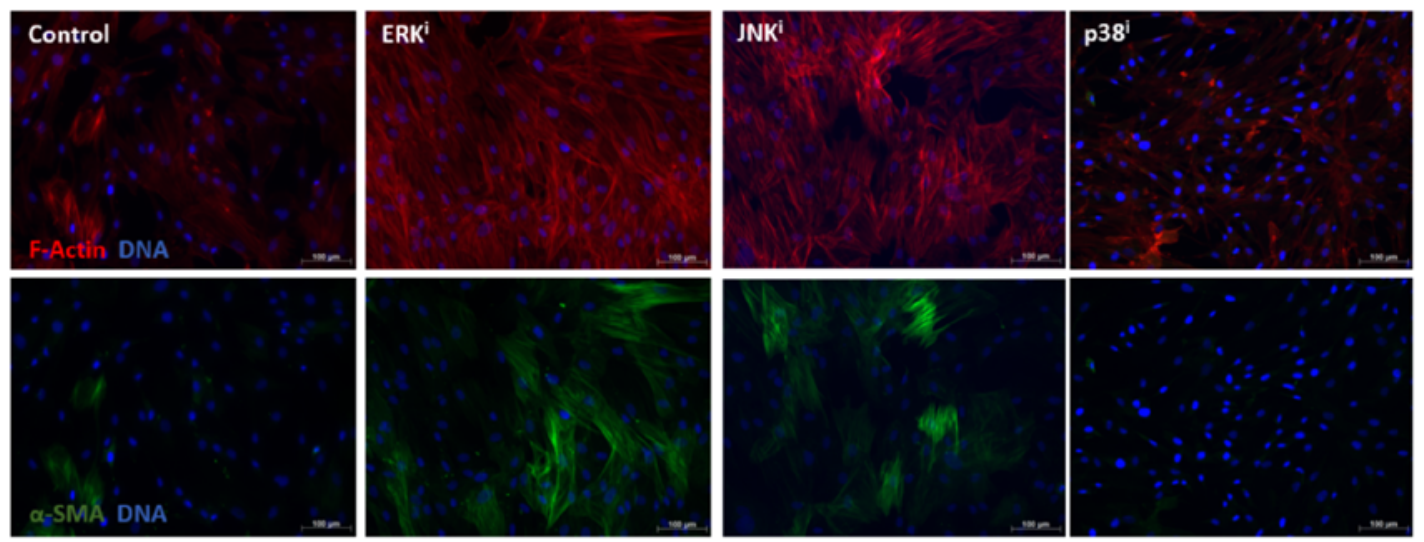

$\mathrm{E}$

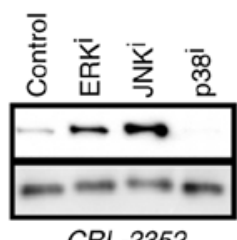

istone $\mathrm{H} 3$

CRL-2352

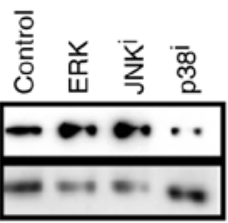

CT-1005

Figure 1. Effects of MAPK inhibitors on fibroblast activation. (A-D) CRL-2097 human dermal fibroblasts were cultured under control conditions, or in the presence of $10 \mu \mathrm{M}$ U0126 (ERK $), 10 \mu \mathrm{M}$ SP600125 (JNK $), 10 \mu \mathrm{M}$ SB202190 (p38 $)$ or $10 \mathrm{ng} / \mathrm{ml}$ exogenous recombinant human TGF- $\beta 1$, and harvested at day 4 in culture. (A) Expression of myofibroblast marker transcripts ACTA2, CNN1 and TAGLN were determined by reverse transcription-quantitative polymerase chain reaction, normalized to the expression of $G A P D H$, and expressed as fold change relative to the expression of control samples. There were 4 biological replicates/condition. Error bars represent standard deviation. Statistics were performed by one-way ANOVA with multiple comparisons using the Holm-Sidak post-hoc test. ${ }^{*} \mathrm{P}<0.05,{ }^{* * *} \mathrm{P}<0.001$ and ${ }^{* * * *} \mathrm{P}<0.0001$. (B) Western blot analysis was performed on myofibroblast markers $\alpha$-SMA and calponin on whole cell lysates. Histone $\mathrm{H} 3$ was used as a loading control. (C) Fibroblasts were fixed and subjected to indirect flow cytometry, and the expression of $\alpha$-SMA was compared with the expression in control fibroblasts. There were 4 biological replicates/condition. Statistics were performed by one-way ANOVA with multiple comparisons using the Holm-Sidak post-hoc test. ${ }^{*} \mathrm{P}<0.05$ and ${ }^{* *} \mathrm{P}<0.01$. (D) Fibroblasts were fixed and stained by immunofluorescence for $\alpha$-SMA, and F-actin was visualized using fluorescently-labeled phalloidin. Nuclei were counterstained with Hoechst. Scale bars, $100 \mu \mathrm{m}$. (E) CRL-2352 and CT-1005 fibroblasts were cultured under control conditions or in the presence of a MAPK inhibitor, and harvested at day 4 in culture. Western blot analysis was performed for detection of $\alpha$-SMA. Histone $\mathrm{H} 3$ was used as a loading control. MAPK, mitogen-activated protein kinase; ERK, extracellular signal-regulated kinase; JNK, c-Jun N-terminal kinase; ANOVA, analysis of variance; ACTA2, $\alpha$-SMA; $\alpha$-SMA, smooth muscle $\alpha$ actin; CNN1, calponin 1; TAGLN, transgelin; TGF- $\beta$, transforming growth factor- $\beta$; ${ }^{\text {i }}$, inhibitor.

conditions $(\mathrm{P}<0.05)($ Fig. $1 \mathrm{C})$. Immunofluorescent imaging revealed that fibroblasts treated with ERK or JNK inhibitors exhibited increased levels of filamentous actin, arranged into stress fibers, and increased fraction of cells stained positive for $\alpha$-SMA, compared with control fibroblasts cultured in the absence of MAPK inhibitors. In contrast, fibroblasts cultured in the presence of p38 inhibitor exhibited a notable reduction of filamentous actin stress fiber formation, as well as a reduction in the expression of $\alpha$-SMA protein (Fig. 1D). Subsequently, the effects of MAPK inhibition on fibroblast activation were confirmed to be generalizable across multiple lines of human dermal fibroblasts, rather than specific to one cell line. It was demonstrated by western blot analysis that two primary adult human dermal fibroblast lines, CRL-2352 and CT-1005, exhibited a qualitatively similar increase in $\alpha$-SMA expression when treated with ERK or JNK inhibitor, and a qualitatively similar decrease in $\alpha$-SMA expression when treated with p38 inhibitor, as was demonstrated in CRL-2097 fibroblasts (Fig. 1E). Collectively, these data demonstrated that culturing fibroblasts with ERK or JNK inhibitors is sufficient to induce fibroblast activation, and that culturing fibroblasts with an inhibitor of p38 is sufficient to antagonize fibroblast activation. Additionally, it was determined that these effects are generalizable across multiple lines of primary human dermal fibroblasts.

Pro-fibrotic gene expression paradigm is induced by inhibition of ERK or JNK and antagonized by inhibition of p38. Since it was demonstrated that MAPK inhibition variably affected fibroblast activation as determined by the expression 

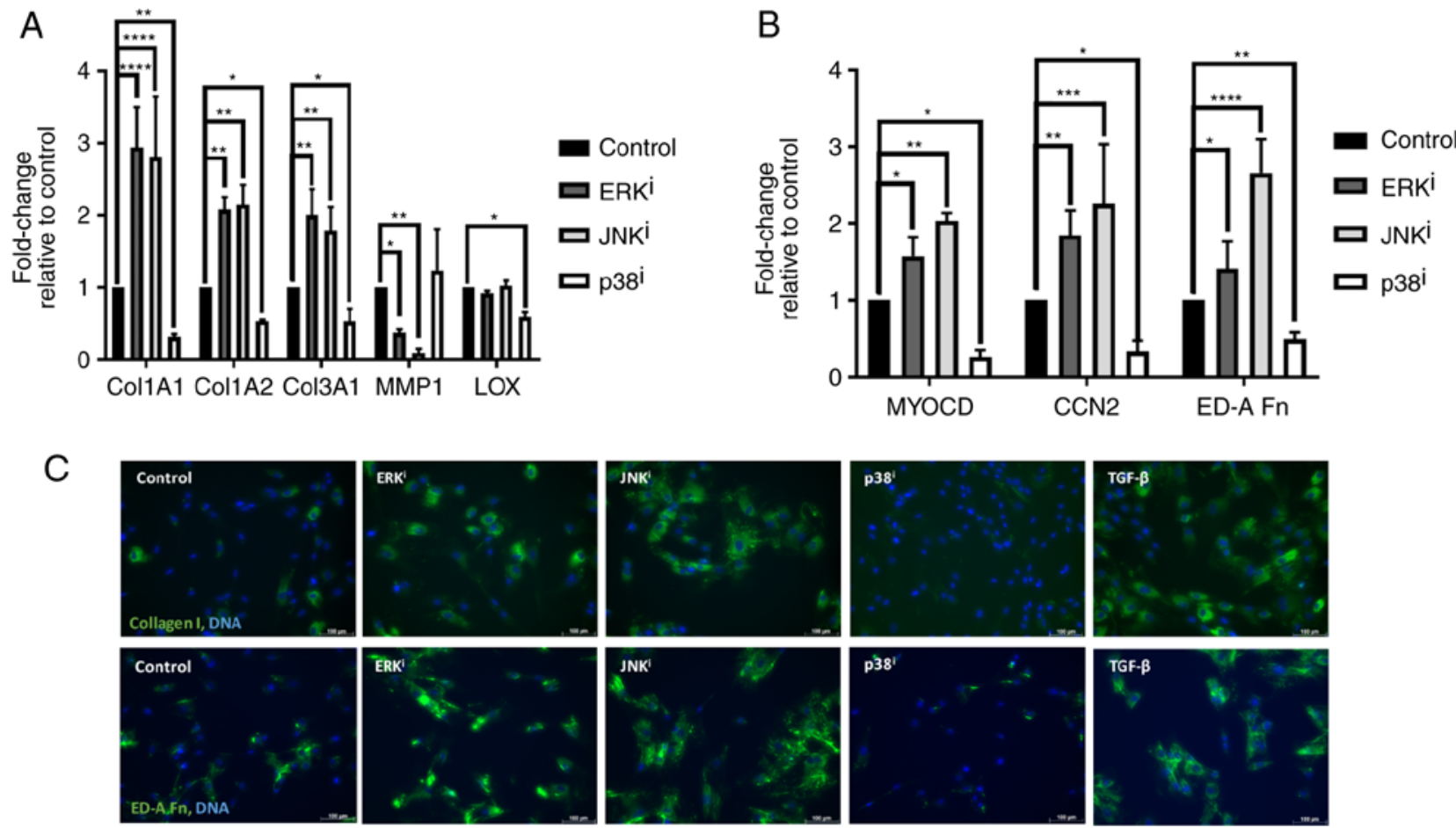

Figure 2. Effects of mitogen-activated protein kinase inhibitors on the ECM. CRL-2097 human dermal fibroblasts were cultured in the presence or absence of $10 \mu \mathrm{M} \mathrm{U} 0126\left(\mathrm{ERK}^{\mathrm{i}}\right), 10 \mu \mathrm{M}$ SP600125 (JNK $)$ or $10 \mu \mathrm{M} \mathrm{SB} 202190\left(\mathrm{p} 38^{\mathrm{i}}\right)$, and harvested at day 4 . Expression levels of ECM-associated transcripts (A) Col1A1, Col1A2, Col3A1, MMP1 and LOX, and (B) MYOCD, CCN2 and ED-A Fn were determined relative to fibroblasts cultured under control conditions by reverse transcription-quantitative polymerase chain reaction. $G A P D H$ expression was used as an internal control. Expression levels per transcript were compared using a one-way analysis of variance and post-hoc Holm-Sidak analysis. ${ }^{*} \mathrm{P}<0.05,{ }^{* *} \mathrm{P}<0.01,{ }^{* * *} \mathrm{P}<0.001$ and ${ }^{* * * * *} \mathrm{P}<0.0001$. There were $2 \leq \mathrm{n} \leq 6$ biological replicates/condition. Error bars represent standard deviation. (C) Fibroblasts were fixed and stained for immunofluorescence for collagen I or ED-A Fn. Nuclei were counterstained with Hoechst. Scale bars, $100 \mu \mathrm{m}$. ECM, extracellular matrix; Col1A1, collagen type $1 \alpha$; MMP1, matrix metallopeptidase 1; LOX, lysyl oxidase; MYOCD, myocardin; CCN2, connective tissue growth factor; ED-A Fn, ED-A fibronectin; ${ }^{\text {, }}$, inhibitor.

of canonical myofibroblast markers, it was subsequently investigated whether this inhibition also affected the expression of other genes associated with ECM deposition and myofibroblast activation. Analysis by RT-qPCR demonstrated that inhibition of ERK or JNK resulted in the significant upregulation ( $\mathrm{P}<0.05$, compared with control fibroblasts) of collagen type $1 \alpha 1$ (CollA1) and CollA2, the genes encoding the chains of type I collagen, and the major ECM component of fibrotic scar tissue, as well as Col3A1, the gene encoding type III collagen. Concordantly, inhibition of ERK or JNK also resulted in significant downregulation of transcription of matrix metallopeptidase 1 (MMP1), the gene encoding the interstitial collagenase MMP1 $(\mathrm{P}<0.05$, compared with control fibroblasts), further indicating an activated fibroblast phenotype associated with excessive deposition of pathologic ECM (Fig. 2A). Inhibition of ERK or JNK also resulted in significantly increased expression of ED-A fibronectin ( $E D-A F n$ ), the transcript encoding the myofibroblast-specific fibronectin isoform known as ED-A Fn, as well as myocardin (MYOCD) and connective tissue growth factor (CCN2), the genes encoding the myogenic transcription factor MYOCD and the pro-fibrotic matricellular protein CNN2, respectively $(\mathrm{P}<0.05$, compared with control fibroblasts) (Fig. 2B). In contrast, inhibition of p38 resulted in significantly decreased expression of these myofibroblast-associated genes, consistent with its apparent ability to antagonize fibroblast activation $(\mathrm{P}<0.05$, compared with control fibroblasts). Inhibition of p38 also resulted in significant downregulation of lysyl oxidase ( $L O X)(\mathrm{P}<0.05$, compared with control fibroblasts), the transcript encoding LOX, a copper-dependent protein that is responsible for the crosslinking of immature collagen precursors into mature collagen fibrils (17) (Fig. 2A). Additionally, immunofluorescent analysis demonstrated that inhibition of ERK or JNK resulted in increased levels of type I collagen and ED-A Fn deposition, and that inhibition of p38 resulted in diminished levels of type I collagen and ED-A Fn deposition (Fig. 2C). Collectively, these data indicate that inhibition of ERK or JNK results in increased deposition of fibrotic ECM through upregulation of transcription of fibrosis-associated and collagen-encoding genes, as well as through downregulation of the expression of the metalloproteinase-encoding gene $M M P 1$. Additionally, these data demonstrated that inhibition of p38 results in decreased deposition of fibrotic ECM through downregulation of fibrosis-associated and collagen-encoding genes, as well as through downregulation of the gene encoding the collagen maturation enzyme LOX.

ERK or JNK inhibition cooperatively enhances TGF- $\beta$ mediated fibroblast activation. As TGF- $\beta 1$ is a fibrogenic cytokine and canonical myofibroblast activator, and specific paradigms of non-canonical TGF- $\beta$ signaling have been demonstrated to proceed via activation of MAPKs, including ERK and JNK (18), the present study determined whether ERK and JNK inhibition would antagonize or enhance TGF- $\beta 1$-mediated fibroblast activation. Western blot analysis demonstrated that treatment with exogenous TGF- $\beta 1$, as well as 
A

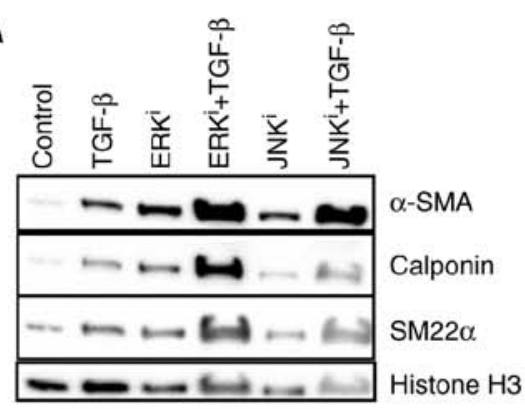

B
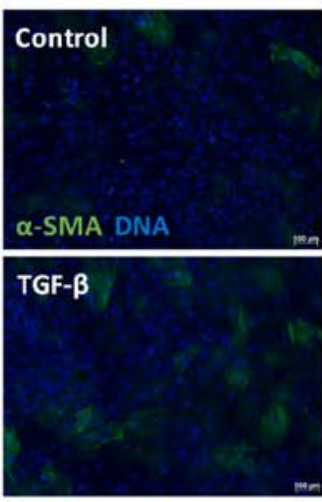
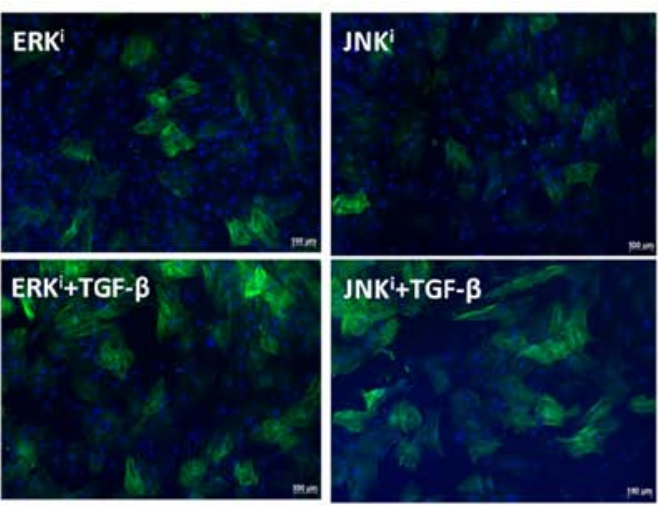

Figure 3. Cooperative effects of mitogen-activated protein kinase inhibition and exogenous TGF- $\beta$ on fibroblast activation. CRL-2097 human dermal fibro-

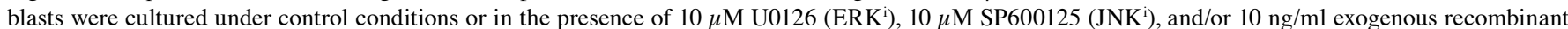
human TGF- $\beta 1$, and analyzed at day 4 in culture. (A) Protein lysates were examined for expression of myofibroblast-associated protein markers $\alpha$-SMA, calponin, and SM22 $\alpha$ by western blot analysis. Histone H3 was used as a loading control. (B) Fibroblasts were fixed and stained for the myofibroblast marker protein $\alpha$-SMA and nuclei were counterstained with Hoechst. Scale bar, $100 \mu \mathrm{m}$. TGF- $\beta$, transforming growth factor- $\beta$; ERK, extracellular signal-regulated kinase; JNK, c-Jun N-terminal kinase; $\alpha$-SMA, smooth muscle $\alpha$ actin; ${ }^{i}$, inhibitor.

treatment with ERK or JNK inhibitors individually, was sufficient to induce the expression of myofibroblast maker proteins $\alpha$-SMA, calponin and SM22 $\alpha$ above the baseline expression levels of control fibroblasts. Additionally, treatment of fibroblasts with TGF- $\beta 1$ and one of the fibrogenic MAPK inhibitors (ERK inhibitor U0126 or JNK inhibitor SP600125) enhanced myofibroblast activation, as indicated by a notable increase in the expression of the identical myofibroblast marker proteins, compared with the expression levels observed in cells treated with exogenous TGF- $\beta 1$ or pro-fibrotic MAPK inhibitor alone (Fig. 3A). These observations were confirmed by immunofluorescence, in which co-treatment of TGF- $\beta 1$ with ERK of JNK inhibitors increased the number and intensity of $\alpha-\mathrm{SMA}^{+}$ cells, compared with treatment with TGF- $\beta 1$ alone (Fig. 3B). Collectively, these data indicated that inhibition of ERK or JNK cooperatively enhances the effects of exogenous TGF- $\beta 1$ on fibroblast activation.

Inhibition of p38 antagonizes fibroblast activation induced by ERK or JNK inhibition. Previous studies implicated MAPK pathways in fibroblast activation, and demonstrated the ability of MAPKs to act as signal transduction mediators of growth factors, demonstrating fibrotic and anti-fibrotic activities (5-15). Since it had been previously demonstrated that different MAPK inhibitors have varied effects on fibroblast activation, and it had been previously demonstrated that inhibition of p38 was sufficient to attenuate fibroblast activation induced by exogenous TGF- $\beta 1$ (15), the present study sought to determine whether these MAPK inhibitors had the ability to antagonize the activity of each other. Measurement of myofibroblast-associated transcripts ACTA2, CNN1 and TAGLN demonstrated that treatment with the $\mathrm{p} 38$ inhibitor antagonized fibroblast activation induced by treatment with ERK or JNK inhibitors $(\mathrm{P}<0.05$ for fibroblasts treated with $\mathrm{ERK}^{\mathrm{i}}$ or $\mathrm{JNK}^{\mathrm{i}}$ and $\mathrm{p} 38^{\mathrm{i}}$ vs. fibroblasts treated with $\mathrm{ERK}^{\mathrm{i}}$ or JNK $^{\mathrm{i}}$ alone) (Fig. 4A). Similarly, western blot analysis demonstrated that treatment with the p38 inhibitor antagonized the expression of $\alpha$-SMA, calponin, and SM22 $\alpha$ protein induced by treatment with ERK or JNK inhibitors, by comparing levels of these proteins in fibroblasts treated with ERK or
JNK and p38 inhibitors vs. fibroblasts treated with ERK or JNK inhibitor alone (Fig. 4B). Immunofluorescent analysis corroborated the Western blot analysis data, demonstrating that treatment with p38 inhibitor decreased the number and intensity of $\alpha-\mathrm{SMA}^{+}$cells, by comparing fluorescence intensity in fibroblasts treated with ERK or JNK and p38 inhibitors vs. fibroblasts treated with ERK or JNK inhibitor alone (Fig. 4C). Collectively, these data indicate that inhibition of p38 is sufficient to antagonize fibroblast activation induced by inhibition of ERK or JNK, as assessed by transcript and protein levels of canonical myofibroblast markers.

Similar effects of ERK and JNK inhibitors on fibroblast activation are not a function of non-specific inhibition of p-ERK by JNK inhibitor. Due to the observation that ERK and JNK inhibitor-mediated fibroblast activation were associated with qualitatively similar expression changes for each gene analyzed, and in consideration of previously reported activity of SP600125 as a modest inhibitor of MAPK kinase 1 (MKK1) (19), the present study sought to confirm that the reason for these similarities was not due to nonspecific inhibitory activity of ERK signaling by the JNK inhibitor. Western blot analysis demonstrated that, while ERK inhibitor treatment decreased ERK phosphorylation at 15-60 min post-treatment as expected, treatment with JNK inhibitor failed to inhibit ERK phosphorylation at these time-points post-treatment (Fig. 5A).

$M A P K$ inhibitors variably affect the transcription of genes encoding TGF- $\beta$ ligands and receptors. Given the importance of TGF- $\beta$ signaling as a ubiquitous central modulator of myofibroblast activation, the present study sought to determine whether the observed effects of MAPK inhibitors on fibroblast activation were accompanied by changes in the expression of TGF- $\beta$-associated genes. Analysis of transcript expression (Fig. 5B) demonstrated that treatment with the ERK inhibitor resulted in the significant upregulation of TGF- $\beta 2$ (TGFB2) and TGF- $\beta R 1$ (TGFBR1), the genes encoding TGF- $\beta 2$ and TGF- $\beta$ R1 respectively, while treatment with the JNK inhibitor resulted in the significant upregulation of TGFB1 and significant downregulation of $T G F B R 3$, the genes encoding 

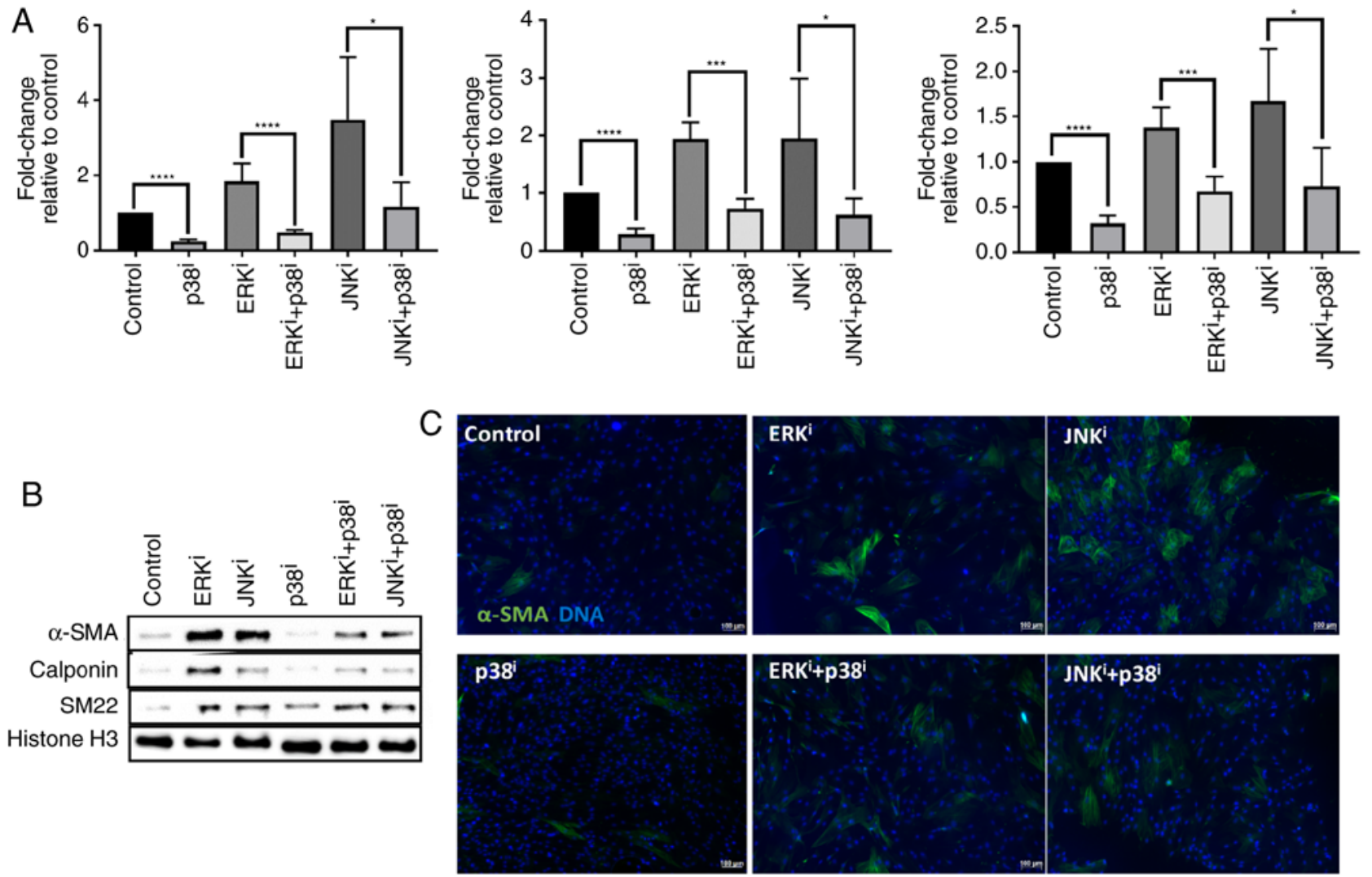

Figure 4. Antagonism of p38 inhibitor towards ERK and JNK inhibitor-mediated fibroblast activation. CRL-2097 human dermal fibroblasts were cultured under control conditions or in the presence of $10 \mu \mathrm{M} \mathrm{U} 0126$ (ERK ${ }^{\mathrm{i}}$ ), $10 \mu \mathrm{M}$ SP600125 (JNK ${ }^{\mathrm{i}}$ ), and/or $10 \mu \mathrm{M} \mathrm{SB} 202190$ (p38 $)$, and analyzed at day 4 in culture. (A) Expression levels of myofibroblast-associated transcripts ACTA2, CNN1 and TAGLN were determined relative to fibroblasts cultured under control conditions by reverse transcription-quantitative polymerase chain reaction. GAPDH expression was used as an internal control. Student's t-tests were performed in order to compare the expression between each culture condition and its $\mathrm{p} 38^{\mathrm{i}}$-treated counterpart. ${ }^{*} \mathrm{P}<0.05,{ }^{* * *} \mathrm{P}<0.001$ and ${ }^{* * * * *} \mathrm{P}<0.0001$. There were 4 biological replicates/condition. Error bars depict standard deviation. (B) Protein lysates were examined for expression of myofibroblast-associated marker proteins $\alpha$-SMA, calponin and SM22 $\alpha$ by western blot analysis. Histone H3 was used as a loading control. (C) Fibroblasts were fixed and stained for the myofibroblast marker protein $\alpha$-SMA and nuclei were counterstained with Hoechst. Scale bars, $100 \mu \mathrm{m}$. ACTA2, $\alpha$-SMA; TAGLN, transgelin; CNN1, calponin 1; ERK, extracellular signal-regulated kinase; JNK, c-Jun N-terminal kinase; $\alpha$-SMA, smooth muscle $\alpha$ actin; ${ }^{\mathrm{i}}$, inhibitor.

TGF- $\beta 1$ and betaglycan, respectively, as well as an unexpected significant downregulation of $T G F B R 2$, the gene encoding TGF- $\beta$ R2 ( $\mathrm{P}<0.05$, compared with control fibroblasts). These data also demonstrated that treatment with the p38 inhibitor decreased the expression of TGFB2 and induced the expression of TGFBR3, in accordance with expectations that $\mathrm{p} 38$ antagonizes the expression of fibrotic TGF- $\beta$ signaling mediators, as indicated by the aforementioned results. Collectively, these data indicated that the effects of the MAPK inhibitor treatments on fibroblast activation may be partially due to their effects on the expression of TGF- $\beta$ signaling-associated genes.

Fibroblast activation induced by ERK or JNK inhibition is antagonized by co-inhibition of TGF- $\beta R 1$. Since ERK and JNK inhibition resulted in fibroblast activation and were associated with modulation of the expression of genes encoding TGF- $\beta$ ligands and receptors, the present study sought to determine whether ERK or JNK inhibitor-mediated fibroblast activation could be antagonized by inhibition of TGF- $\beta$ signaling. A dose-response curve demonstrated that treatment of fibroblasts with $100 \mathrm{nM}$ Repsox, a TGF- $\beta$ R1 inhibitor, was sufficient to decrease basal expression of myofibroblast markers $\alpha$-SMA and calponin (Fig. 6A). Thus, $100 \mathrm{nM}$ Repsox was selected for use in subsequent experiments. Notably, increasing concentrations of Repsox up to $10 \mu \mathrm{M}$ were determined to substantially induce fibroblast activation, as demonstrated by notable upregulation of myofibroblast-associated proteins $\alpha$-SMA and calponin, in contrast to intended effects as an antagonist of TGF- $\beta$ signaling.

Western blot analysis demonstrated that treatment with $100 \mathrm{nM}$ TGF- $\beta$ R 1 inhibitor partially antagonized ERK and JNK inhibitor-mediated fibroblast activation, as indicated by the expression levels of $\alpha$-SMA protein (Fig. 6B). Densitometry and subsequent statistical analysis confirmed that the antagonistic effects of TGF- $\beta$ R1 inhibitor on ERK inhibitor-mediated, JNK inhibitor-mediated and exogenous TGF- $\beta 1$-mediated fibroblast activation were statistically significant $\left(\mathrm{P}<0.05\right.$ for fibroblasts treated with ERK ${ }^{\mathrm{i}}+\mathrm{TGFBR} 1^{\mathrm{i}}$, compared with ERK ${ }^{\mathrm{i}}, \mathrm{JNK}^{\mathrm{i}}+\mathrm{TGFBR} 1^{\mathrm{i}}$, compared with $\mathrm{JNK}^{\mathrm{i}}$, and TGF- $\beta+$ TGF- $\beta$ R $1^{i}$, compared with TGF- $\beta$; Fig. $6 \mathrm{C}$ ). Collectively, these data demonstrate that fibroblast activation induced by small molecule-mediated inhibition of ERK or JNK is partially dependent on signaling via TGF- $\beta$ R 1 .

\section{Discussion}

One of the dominant mechanisms by which a cell receives signals from its extracellular environment and converts these 


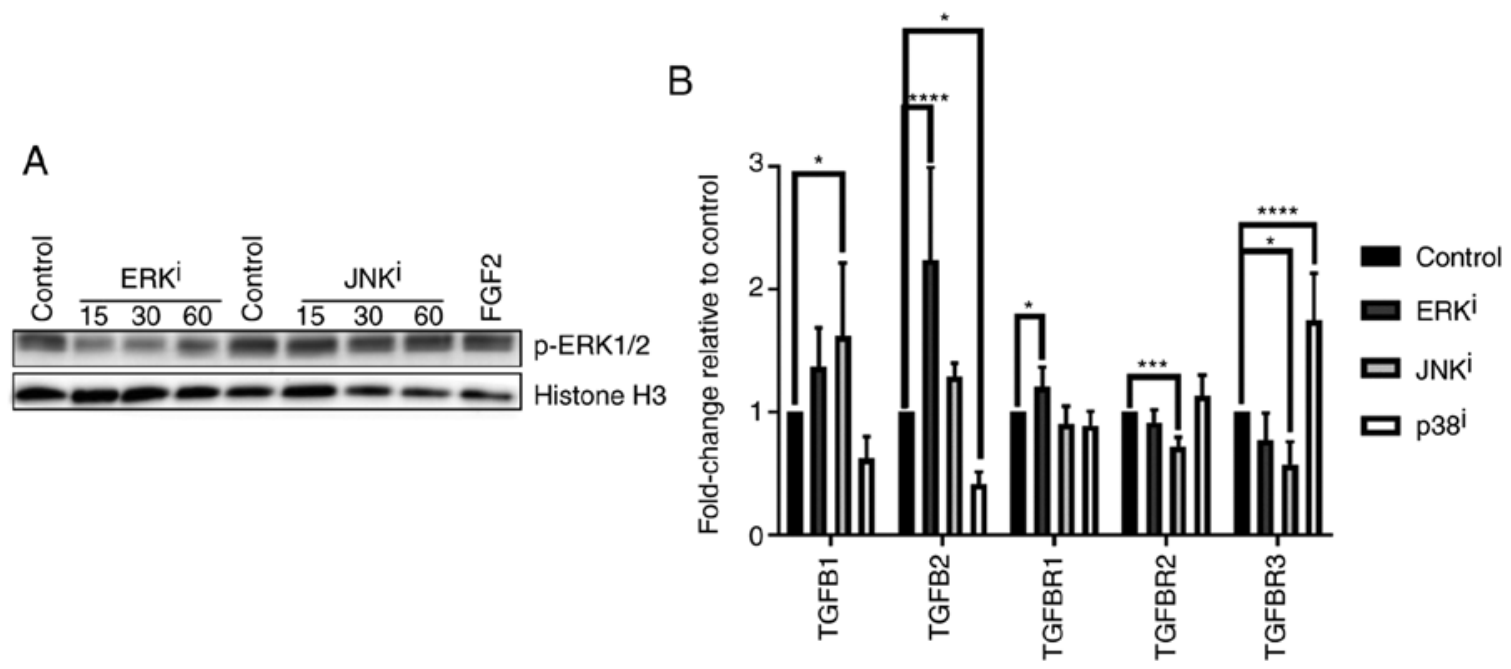

Figure 5. TGF- $\beta$-associated gene expression profiles induced by treatment with mitogen-activated protein kinase inhibitors. (A) CRL-2097 human dermal fibroblasts were cultured for 15-60 min in the presence or absence of $10 \mu \mathrm{M} \mathrm{U} 0126$ (ERK ${ }^{\mathrm{i}}$ ) or $10 \mu \mathrm{M} \mathrm{SP} 600125$ (JNK ${ }^{\mathrm{i}}$ ) and subjected to western blot analysis for p-ERK1/2. Histone $\mathrm{H} 3$ was used as a loading control. Fibroblasts incubated with recombinant human FGF2 for 30 min were used as a positive control for p-ERK1/2 expression. (B) CRL-2097 human dermal fibroblasts were cultured in the presence or absence of $10 \mu \mathrm{M}$ U0126 (ERK $), 10 \mu \mathrm{M} \mathrm{SP600125} \mathrm{(JNK})$ or $10 \mu \mathrm{M}$ SB202190 (p38i) until day 4. Expression levels of TGF- $\beta$-associated transcripts TGFB1, TGFB2, TGFBR1,TGFBR2 and TGFBR3 were determined relative to fibroblasts cultured under control conditions by reverse transcription-quantitative polymerase chain reaction. GAPDH expression was used as an internal control. Expression levels per transcript were compared using an one-way analysis of variance and post-hoc Holm-Sidak analysis. ${ }^{*} \mathrm{P}<0.05$, ${ }^{* * * *} \mathrm{P}<0.001$ and ${ }^{* * * * *} \mathrm{P}<0.0001$. There were 6 biological replicates/condition. Error bars represent the standard deviation. TGFB1, transforming growth factor- $\beta 1$; TGFBR 1 , TGF- $\beta$ receptor 1; p-ERK, phospho-extracellular signal-regulated kinase; JNK, c-Jun N-terminal kinase; FGF2, fibroblast growth factor 2; ${ }^{\mathrm{i}}$, inhibitor.

signals to actionable responses is through signaling via growth factors (20-23). Growth factors are one vehicle used to relay signals containing information regarding the extracellular environment in order to induce a functional response in cells. Growth factor signaling pathways are defined by the ligands that initiate the cellular signal, the growth factor receptor that transduces this signal from the extracellular environment across the plasma membrane, and the intracellular effector proteins that work to initiate and propagate a functional response in the target cell (20-23). The mechanisms by which growth factor/growth factor receptor complexes transduce a signal and result in cellular activity vary among different pathways, but one of the most common paradigms is transduction via MAPK signaling $(24,25)$. As myofibroblasts are one of many important effector cells in the mammalian wound healing response, and as fibroblasts are activated to myofibroblasts by TGF- $\beta$ signaling (3), the present study investigated the effects of MAPK inhibitors on TGF- $\beta$ signaling and fibroblast activation.

The present data demonstrates that treatment of proliferative fibroblasts with ERK or JNK inhibitors is sufficient to induce fibroblast activation and upregulate the expression of myofibroblast marker proteins, and that treatment with a p38 inhibitor is sufficient to antagonize fibroblast activation (Fig. 1), in accordance with our previously published data (15). These fibroblast activation dynamics also predicted the changes observed in ECM-associated gene and protein expression (Fig. 2), where it was determined that treatment of fibroblasts with ERK or JNK inhibitors induced a relative gene expression profile associated with fibroblast activation and conducive to fibrotic ECM deposition. Additionally, it was indicated that treatment of fibroblasts with a p38 inhibitor induced a relative gene expression profile contrary to fibroblast activation and averse to pro-fibrotic ECM deposition.
There is precedent for the role of $\mathrm{p} 38$ in fibroproliferative diseases. Constitutive activation of $\mathrm{p} 38$ was demonstrated in fibroblasts derived from patients with scleroderma, and inhibition of p38 activation via small molecules or transient transfection with a p38 dominant negative mutant was sufficient to reduce the high levels of type I collagen and fibronectin associated with scleroderma fibroblasts (26). Cardiac fibroblast-specific deletion of MAPK14, the gene encoding $\mathrm{p} 38 \alpha$, resulted in a reduction of fibrotic damage induced at a later time in a murine ischemic model, and deletion of MAPK14 in existing myofibroblasts resulted in increased tolerance to myocardial infarct injury. In concordance with these data, cardiac fibroblast-specific overexpression of MKK6, which is responsible for activation of p38 signaling, resulted in an enhanced fibrotic response (11). In a mouse model of nephropathic fibrosis, small molecule-mediated inhibition, alone and cooperatively alongside administration of a TGF- $\beta \mathrm{R} 1$ inhibitor, of p38 reduced intestinal fibrosis (9). This indicates that the pro-fibrotic effects of $\mathrm{p} 38$ signaling are partially distinct from canonical TGF- $\beta /$ TGF- $\beta R /$ SMAD signaling. This is plausible considering the understanding of the ability of TGF- $\beta$ R 1 and TGF- $\beta$ R 2 to directly contribute to MAPK phosphorylation $(27,28)$, as well as in light of the numerous examples of crosstalk between TGF- $\beta$ and MAPK signaling (29-35). Collectively, these data alongside other reports demonstrating the anti-fibrotic effects of $\mathrm{p} 38$ inhibition (36-40), indicate that p38 activation is necessary for the differentiation and maintenance of myofibroblasts, such that inhibition of p38 or its downstream effectors may be a viable therapeutic option for specific pathological fibroproliferative states.

It was also demonstrated that treatment with ERK or JNK inhibitors cooperatively enhanced fibroblast activation induced by treatment with exogenous TGF- $\beta 1$ (Fig. 3 ), and that treatment with a p38 inhibitor partially inhibited fibroblast activation 
A

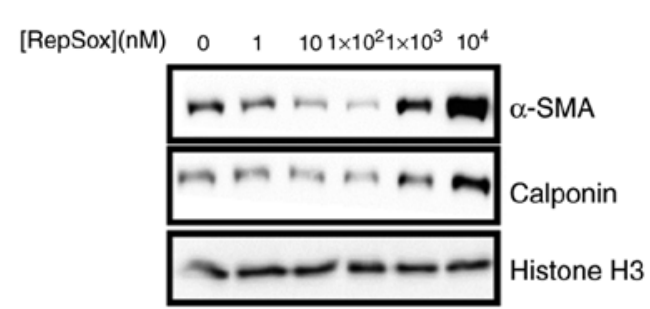

B

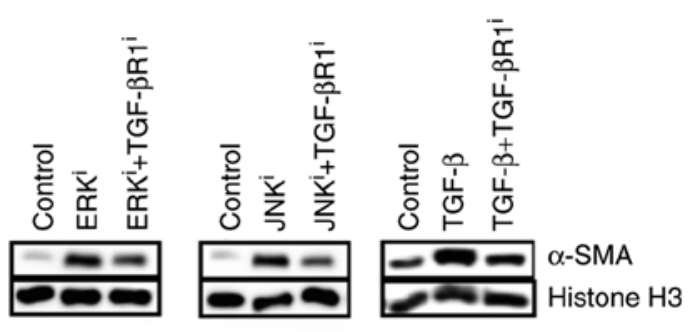

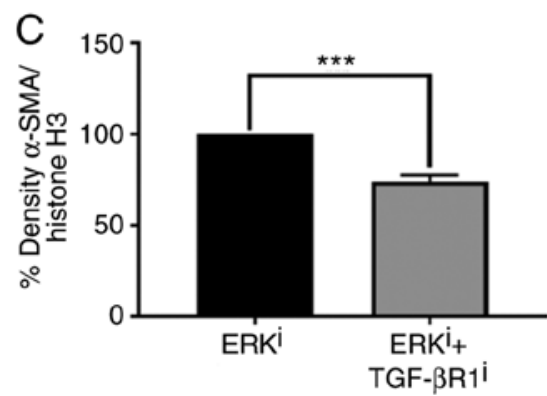
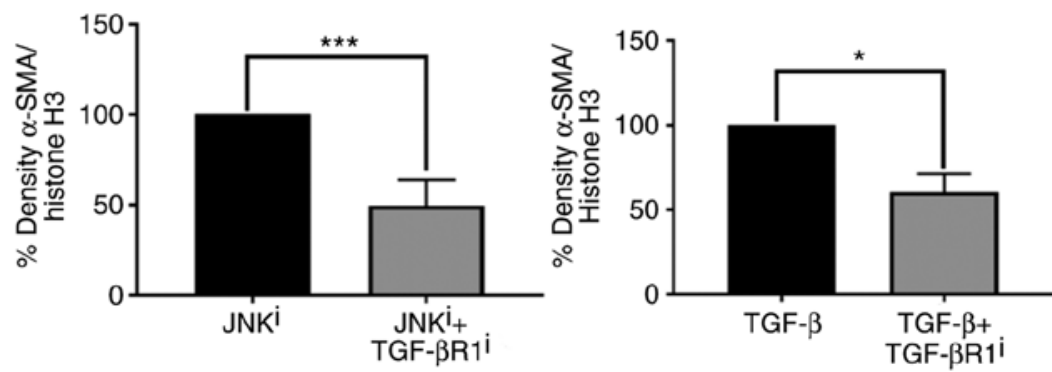

Figure 6. Effects of TGF- $\beta$ R1 inhibition on fibroblast activation induced by ERK or JNK inhibitors. (A) CRL-2097 human dermal fibroblasts were cultured in the presence or absence of the indicated concentration of the TGF- $\beta$ R1 inhibitor RepSox until day 4 and then subjected to Western blot analysis for myofibroblast markers $\alpha$-SMA and calponin. Histone H3 was used as a loading control. (B) CRL-2097 human dermal fibroblasts were cultured in the presence or absence of $10 \mu \mathrm{M}$ U0126 (ERK $\left.{ }^{\mathrm{i}}\right), 10 \mu \mathrm{M}$ SP600125 (JNK $\left.{ }^{\mathrm{i}}\right), 10 \mathrm{ng} / \mathrm{ml}$ TGF- $\beta 1$ and $100 \mathrm{nM}$ RepSox until day 4 and then subjected to western blot analysis for myofibroblast marker $\alpha$-SMA. Histone H3 was used as a loading control. (C) Western blots were analyzed using densitometry, and relative density of $\alpha$-SMA/Histone H3 was compared for each mitogen-activated protein kinase inhibitor-treated or TGF- $\beta 1$-treated sample compared with its corresponding TGF- $\beta$ R 1 inhibitor-treated sample. Statistical significance was determined using a two-tailed Student's t-test. ${ }^{*} \mathrm{P}<0.05$ and ${ }^{* * *} \mathrm{P}<0.001$. There were $2 \leq \mathrm{n} \leq 4$ biological replicates/condition. Error bars depict the standard deviation. TGF- $\beta$ R1, transforming growth factor- $\beta$ receptor 1; ERK, extracellular signal-regulated kinase; JNK, c-Jun N-terminal kinase; $\alpha$-SMA, smooth muscle $\alpha$ actin; ${ }^{i}$, inhibitor.

induced by treatment with ERK or JNK inhibitors (Fig. 4), indicating crosstalk between the MAPK and TGF- $\beta$ pathways, as well as between individual MAPK pathways. Additionally, it was determined that fibroblasts treated with MAPK inhibitors demonstrated distinct expression profiles of TGF- $\beta$-associated genes, compared with control fibroblasts (Fig. 5). Notably, these changes in gene expression spanned TGF- $\beta$ ligands and receptors, including the non-signal transducing receptor TGF- $\beta$ R3, also known as betaglycan, which has the ability to sequester pro-fibrotic TGF- $\beta$ ligands $(41,42)$. Treatment with a JNK inhibitor downregulated betaglycan transcript expression, and treatment with a p38 inhibitor upregulated betaglycan transcript expression, both of which were expected considering the observation that JNK inhibition induces and p38 inhibition antagonizes fibroblast activation. Accordingly, a synthetic peptide derived from the ligand-binding domain of betaglycan has been demonstrated to attenuate fibrosis in in vivo models of myocardial (43), hepatic (44) and dermal fibrosis (45), and stable overexpression of betaglycan attenuates TGF- $\beta$ signaling (SMAD-dependent and SMAD-independent) in lung fibroblasts (46). It was also determined that the activation of fibroblasts mediated by treatment with ERK or JNK inhibitors was partially antagonized by co-treatment with a small molecule inhibitor of TGF- $\beta$ R1 (Fig. 6), indicating that fibroblast activation induced by these inhibitors is partially due to their effects on TGF- $\beta /$ TGF- $\beta$ R activity. The present data demonstrating that treatment with JNK inhibitor induced fibroblast activation and a pro-fibrotic TGF- $\beta$ gene expression paradigm are also consistent with previous reports indicating the ability of the JNK inhibitor SP600125 to induce SMAD phosphorylation and cooperate with exogenous TGF- $\beta$ to enhance SMAD signaling $(47,48)$.
The mechanisms through which treatment with ERK and JNK inhibitors induces fibroblast activation downstream of their effects on MAPK signaling, even in the absence of exogenous stimulation with a growth factor, are not completely understood, but a number of possibilities can be considered. It is possible that ERK or JNK inhibitors are inhibiting basal levels of MAPK signaling resulting from serum stimulation or from autocrine or paracrine signaling of secreted growth factors, including fibroblast growth factors (49). Additionally, the regulatory linker region of SMAD proteins has been demonstrated to undergo phosphorylation by ERK $(50,51)$ and JNK $(52,53)$, among numerous other kinases (18). As SMAD signaling is critical to fibroblast activation and fibrosis induced by TGF- $\beta$, modulation of SMAD signaling via MAPK inhibition may be partially responsible for the effects of MAPK inhibitors on fibroblast activation, perhaps at least in part through further modulation of TGF- $\beta$ signaling at the transcriptional level (Fig. 5).

The present data shed light on the effects of MAPK inhibition on human fibroblasts, in the context of fibroblast activation and subsequent pro-fibrotic, myofibroblast-associated gene expression. Developing an understanding of MAPK inhibitor effects on fibroblast phenotype is important, particularly considering the interest in tyrosine kinase inhibitors as therapeutics for various diseases, including fibrotic diseases (54-57). As further research yields an improved understanding of the effects of MAPK inhibitors on fibroblasts, and the mechanisms through which these activities are induced, the potential benefits and pitfalls of modulating these highly pleiotropic pathways for treatment or prevention of fibroproliferative diseases can be assessed in an improved manner. 


\section{Acknowledgements}

The authors would like to thank Ms Victoria Huntress (Worcester Polytechnic Institute, Worcester, MA, USA), of the WPI microscopy core, for her assistance with fluorescent imaging. The abstract was presented at Experimental Biology 2018 on April 21-25 2018 in San Diego, CA and published as abstract no. 660.6 in The FASEB Journal (Supp 1): 2018.

\section{Funding}

The present study was supported by a National Institutes of Health award to Tanja Dominko (grant no. R01GM85456) and the National Science Foundation Integrative Graduate Education and Research Traineeship (grant no. DGE 1144804) awarded to David Dolivo.

\section{Availability of data and materials}

The datasets used and/or analyzed during the current study are available from the corresponding author on reasonable request.

\section{Authors' contributions}

DD, SL and TD conceived the experiments. DD and SL performed the experiments. DD drafted the manuscript. DD, SL and TD edited and revised manuscript. DD, SL and TD approved the final draft of the manuscript prior to submission.

\section{Ethics approval and consent to participate}

Not applicable.

\section{Patient consent for publication}

Not applicable.

\section{Competing interests}

The authors declare that they have no competing interests.

\section{References}

1. Wynn TA: Common and unique mechanisms regulate fibrosis in various fibroproliferative diseases. J Clin Invest 117: 524-529, 2007.

2. Zeisberg M and Kalluri R: Cellular mechanisms of tissue fibrosis 1. Common and organ-specific mechanisms associated with tissue fibrosis. Am J Physiol Cell Physiol 304: C216-C225, 2013

3. Hinz B: Myofibroblasts. Exp Eye Res 142: 56-70, 2016.

4. Cargnello M and Roux PP: Activation and function of the MAPKs and their substrates, the MAPK-activated protein kinases. Microbiol Mol Biol Rev 75: 50-83, 2011.

5. Mulsow JJ, Watson RW, Fitzpatrick JM and O'connell PR: Transforming growth factor-beta promotes pro-fibrotic behavior by serosal fibroblasts via PKC and ERK1/2 mitogen activated protein kinase cell signaling. Ann Surg 242: 880-889, 2005.

6. Stambe C, Atkins RC, Tesch GH, Masaki T, Schreiner GF and Nikolic-Paterson DJ: The role of $\mathrm{p} 38 \alpha$ mitogen-activated protein kinase activation in renal fibrosis. J Am Soc Nephrol 15: 370-379, 2004.

7. Grella A, Kole D, Holmes W and Dominko T: FGF2 overrides TGF $\beta 1$-driven integrin ITGA11 expression in human dermal fibroblasts. J Cell Biochem 117: 1000-1008, 2016.
8. Wu W, Muchir A, Shan J, Bonne G and Worman HJ: Mitogen-activated protein kinase inhibitors improve heart function and prevent fibrosis in cardiomyopathy caused by mutation in lamin A/C gene. Circulation 123: 53-61, 2011.

9. Li J, Campanale NV, Liang RJ, Deane JA, Bertram JF and Ricardo SD: Inhibition of p38 mitogen-activated protein kinase and transforming growth factor- $\beta 1 /$ Smad signaling pathways modulates the development of fibrosis in adriamycin-induced nephropathy. Am J Pathol 169: 1527-1540, 2006.

10. See F, Thomas W, Way K, Tzanidis A, Kompa A, Lewis D, Itescu S and Krum H: p38 mitogen-activated protein kinase inhibition improves cardiac function and attenuates left ventricular remodeling following myocardial infarction in the rat. J Am Coll Cardiol 44: 1679-1689, 2004.

11. Molkentin JD, Bugg D, Ghearing N, Dorn LE, Kim P, Sargent MA, Gunaje J, Otsu K and Davis J: Fibroblast-specific genetic manipulation of p38 Mitogen-activated protein kinase in vivo reveals its central regulatory role in fibrosis. Circulation 136: 549-561, 2017.

12. Furukawa F, Matsuzaki K, Mori S, Tahashi Y, Yoshida K, Sugano Y, Yamagata H, Matsushita M, Seki T, Inagaki Y, et al: p38 MAPK mediates fibrogenic signal through Smad3 phosphorylation in rat myofibroblasts. Hepatology 38: 879-889, 2003.

13. Meyer-Ter-Vehn T, Gebhardt S, Sebald W, Buttmann M, Grehn F, Schlunck G and Knaus P: p38 inhibitors prevent TGF-beta-induced myofibroblast transdifferentiation in human Tenon fibroblasts. Invest Ophthalmol Vis Sci 47: 1500-1509, 2006.

14. Sousa AM, Liu T, Guevara O, Stevens J, Fanburg BL, Gaestel M, Toksoz D and Kayyali US: Smooth muscle alpha-actin expression and myofibroblast differentiation by TGFbeta are dependent upon MK2. J Cell Biochem 100: 1581-1592, 2007.

15. Dolivo DM, Larson SA and Dominko T: FGF2-mediated attenuation of myofibroblast activation is modulated by distinct MAPK signaling pathways in human dermal fibroblasts. J Dermatol Sci 88: 339-348, 2017.

16. Schmittgen TD and Livak KJ: Analyzing real-time PCR data by the comparative CT method. Nat Protoc 3: 1101-1108, 2008.

17. Kagan HM and Li W: Lysyl oxidase: Properties, specificity, and biological roles inside and outside of the cell. J Cell Biochem 88: 660-672, 2003

18. Burch ML, Zheng W and Little PJ: Smad linker region phosphorylation in the regulation of extracellular matrix synthesis. Cell Mol Life Sci 68: 97-107, 2011

19. Bain J, Plater L, Elliott M, Shpiro N, Hastie CJ, Mclauchlan H, Klevernic I, Arthur JS, Alessi DR and Cohen P: The selectivity of protein kinase inhibitors: A further update. Biochem J 408: 297-315, 2007.

20. Maddaluno L, Urwyler C and Werner S: Fibroblast growth factors: Key players in regeneration and tissue repair. Development 144: 4047-4060, 2017.

21. Johnson KE and Wilgus TA: Vascular endothelial growth factor and angiogenesis in the regulation of cutaneous wound repair. Adv Wound Care (New Rochelle) 3: 647-661, 2014.

22. Barrientos S, Stojadinovic O, Golinko MS, Brem H and Tomic-Canic M: Growth factors and cytokines in wound healing. Wound Repair Regen 16: 585-601, 2008.

23. Werner S and Grose R: Regulation of wound healing by growth factors and cytokines. Physiol Rev 83: 835-870, 2003.

24. Krishna $M$ and Narang H: The complexity of mitogen-activated protein kinases (MAPKs) made simple. Cell Mol Life Sci 65: 3525-3544, 2008

25. Plotnikov A, Zehorai E, Procaccia S and Seger R: The MAPK cascades: Signaling components, nuclear roles and mechanisms of nuclear translocation. Biochim Biophys Acta 1813: 1619-1633, 2011.

26. Ihn H, Yamane $\mathrm{K}$ and Tamaki K: Increased phosphorylation and activation of mitogen-activated protein kinase p38 in scleroderma fibroblasts. J Invest Dermatol 20: 247-255, 2005.

27. Galliher AJ and Schiemann WP: Src phosphorylates Tyr284 in TGF-beta type II receptor and regulates TGF-beta stimulation of p38 MAPK during breast cancer cell proliferation and invasion. Cancer Res 67: 3752-3758, 2007.

28. Lee MK, Pardoux C, Hall MC, Lee PS, Warburton D, Qing J, Smith SM and Derynck R: TGF-beta activates Erk MAP kinase signalling through direct phosphorylation of ShcA. EMBO J 26: 3957-3967, 2007.

29. Chapnick DA, Warner L, Bernet J, Rao T and Liu X: Partners in crime: The TGF $\beta$ and MAPK pathways in cancer progression. Cell Biosci 1: 42, 2011. 
30. Xie L, Law BK, Chytil AM, Brown KA, Aakre ME and Moses HL: Activation of the Erk pathway is required for TGF-beta1-induced EMT in vitro. Neoplasia 6: 603-610, 2004.

31. Gui T, Sun Y, Shimokado A and Muragaki Y: The roles of mitogen-activated protein kinase pathways in TGF- $\beta$-induced epithelial-mesenchymal transition. J Signal Transduct 2012: 289243, 2012.

32. Selvamurugan N, Kwok S, Alliston T, Reiss M and Partridge NC: Transforming growth factor-beta1 regulation of collagenase-3 expression in osteoblastic cells by cross-talk between the Smad and MAPK signaling pathways and their components, Smad2 and Runx2. J Biol Chem 279: 19327-19334, 2004.

33. Terai K, Call MK, Liu H, Saika S, Liu CY, Hayashi Y, Chikama T, Zhang J, Terai N, Kao CW and Kao WW: Crosstalk between TGF-beta and MAPK signaling during corneal wound healing. Invest Ophthalmol Vis Sci 52: 8208-8215, 2011.

34. Xiao YQ, Malcolm K, Worthen GS, Gardai S, Schiemann WP, Fadok VA, Bratton DL and Henson PM: Cross-talk between ERK and p38 MAPK mediates selective suppression of pro-inflammatory cytokines by transforming growth factor- $\beta$. J Biol Chem 277: 14884-14893, 2002.

35. Kolosova I, Nethery D and Kern JA: Role of Smad2/3 and p38 MAP kinase in TGF- $\beta 1$-induced epithelial-mesenchymal transition of pulmonary epithelial cells. J Cell Physiol 226: 1248-1254, 2011.

36. Nishida M, Okumura Y, Sato H and Hamaoka K: Delayed inhibition of p38 mitogen-activated protein kinase ameliorates renal fibrosis in obstructive nephropathy. Nephrol Dial Transplant 23: 2520-2524, 2008.

37. Raia V, Maiuri L, Ciacci C, Ricciardelli I, Vacca L, Auricchio S, Cimmino M, Cavaliere M, Nardone M, Cesaro A, et al: Inhibition of p38 mitogen activated protein kinase controls airway inflammation in cystic fibrosis. Thorax 60: 773-780, 2005.

38. Gao F, Wang Y, Li S, Wang Z, Liu C and Sun D: Inhibition of p38 mitogen-activated protein kinases attenuates renal interstitial fibrosis in a murine unilateral ureteral occlusion model. Life Sci 167: 78-84, 2016.

39. Sugiyama N, Kohno M and Yokoyama T: Inhibition of the p38 MAPK pathway ameliorates renal fibrosis in an NPHP2 mouse model. Nephrol Dial Transplant 27: 1351-1358, 2012.

40. Wilde JM, Gumucio JP, Grekin JA, Sarver DC, Noah AC, Ruehlmann DG, Davis ME, Bedi A and Mendias CL: Inhibition of p38 mitogen-activated protein kinase signaling reduces fibrosis and lipid accumulation after rotator cuff repair. J Shoulder Elbow Surg 25: 1501-1518, 2016

41. López-Casillas F, Payne HM, Andres JL and Massagué J: Betaglycan can act as a dual modulator of TGF-beta access to signaling receptors: Mapping of ligand binding and GAG attachment sites. J Cell Biol 124: 557-568, 1994

42. Eickelberg O, Centrella M, Reiss M, Kashgarian M and Wells RG: Betaglycan Inhibits TGF-beta signaling by preventing type I-type II receptor complex formation. Glycosaminoglycan modifications alter betaglycan function. J Biol Chem 277: 823-829, 2002.

43. Hermida N, López B, González A, Dotor J, Lasarte JJ, Sarobe P, Borrás-Cuesta $\mathrm{F}$ and Díez J: A synthetic peptide from transforming growth factor-betal type III receptor prevents myocardial fibrosis in spontaneously hypertensive rats. Cardiovasc Res 81 : 601-609, 2009
44. Ezquerro IJ, Lasarte JJ, Dotor J, Castilla-Cortazar I, Bustos M, Peñuelas I, Blanco G, Rodríguez C, Lechuga Mdel C, Greenwel $\mathrm{P}$, et al: A synthetic peptide from transforming growth factor beta type III receptor inhibits liver fibrogenesis in rats with carbon tetrachloride liver injury. Cytokine 22: 12-20, 2003.

45. Santiago B, Gutierrez-Cañas I, Dotor J,Palao G, Lasarte JJ, Ruiz J, Prieto J, Borrás-Cuesta F and Pablos JL: Topical application of a peptide inhibitor of transforming growth factor-betal ameliorates bleomycin-induced skin fibrosis. J Invest Dermatol 125 : 450-455, 2005.

46. Ahn JY, Park S, Yun YS and Song JY: Inhibition of type III TGF- $\beta$ receptor aggravates lung fibrotic process. Biomed Pharmacother 64: 472-476, 2010.

47. Lin Y, Zhang B, Liang H, Lu Y, Ai X, Zhang B and Chen X: JNK inhibitor SP600125 enhances TGF- $\beta$-induced apoptosis of RBE human cholangiocarcinoma cells in a Smad-dependent manner. Mol Med Rep 8: 1623-1629, 2013.

48. Wu S, Kasisomayajula K, Peng J and Bancalari E: Inhibition of JNK enhances TGF-beta1-activated Smad2 signaling in mouse embryonic lung. Pediatr Res 65: 381-386, 2009.

49. Turner $\mathrm{N}$ and Grose R: Fibroblast growth factor signalling: From development to cancer. Nat Rev Cancer 10: 116-129, 2010.

50. Hough C, Radu M and Doré JJ: Tgf-beta induced Erk phosphorylation of smad linker region regulates smad signaling. PLoS One 7: e42513, 2012.

51. Hayashida T, Decaestecker M and Schnaper HW: Cross-talk between ERK MAP kinase and Smad signaling pathways enhances TGF-beta-dependent responses in human mesangial cells. FASEB J 17: 1576-1578, 2003.

52. Engel ME, McDonnell MA, Law BK and Moses HL: Interdependent SMAD and JNK signaling in transforming growth factor-beta-mediated transcription. J Biol Chem 274: 37413-37420, 1999.

53. Mori S, Matsuzaki K, Yoshida K, Furukawa F, Tahashi Y, Yamagata H, Sekimoto G, Seki T, Matsui H, Nishizawa M, et al: TGF-beta and HGF transmit the signals through JNK-dependent Smad2/3 phosphorylation at the linker regions. Oncogene 23: 7416-7429, 2004

54. Qu K, Huang Z, Lin T, Liu S, Chang H, Yan Z, Zhang H and Liu C: New Insight into the anti-liver fibrosis effect of multitargeted tyrosine kinase inhibitors: From molecular target to clinical trials. Front Pharmacol 6: 300, 2016.

55. Kompa AR: Do p38 mitogen-activated protein kinase inhibitors have a future for the treatment of cardiovascular disease? J Thorac Dis 8: E1068-E1071, 2016.

56. Raghu G and Selman M: Nintedanib and pirfenidone. New antifibrotic treatments indicated for idiopathic pulmonary fibrosis offer hopes and raises questions. Am Thoracic Soc 191: 252-254, 2015.

57. Hartmann JT, Haap M, Kopp HG and Lipp HP: Tyrosine kinase inhibitors-a review on pharmacology, metabolism and side effects. Curr Drug Metab 10: 470-481, 2009.

This work is licensed under a Creative Commons Attribution-NonCommercial-NoDerivatives 4.0 International (CC BY-NC-ND 4.0) License. 